\title{
1 Comparative net energy analysis of renewable electricity and carbon capture and storage
} Sgouris Sgouridis ${ }^{*}$, Michael Carbajales-Dale ${ }^{\#}$ Denes Csala ${ }^{+}$, Matteo Chiesa ${ }^{*}$, Ugo Bardi ${ }^{\infty}$

* Masdar Institute, Khalifa University, Abu Dhabi, UAE

\# Clemson University, SC 29634, USA

${ }^{+}$Lancaster University, Lancaster UK

${ }^{\infty}$ University of Florence, Sesto Fiorentino, IT

\begin{abstract}
Carbon capture and storage (CCS) for fossil fuel power plants is perceived as a critical technology for climate mitigation. Nevertheless, limited installed capacity to date raises concerns about CCS ability to scale sufficiently. Conversely, scalable renewable electricity installations -solar and wind - are already deployed at scale and have demonstrated a rapid expansion potential. Here we show that power sector $\mathrm{CO}_{2}$ emission reductions accomplished by investing in renewable technologies generally provide a better energetic return than CCS. We estimate the electrical Energy-Return-on-Energy-Invested ratio of CCS projects accounting for their operational and infrastructural energy penalties to range between 6.6:1 and 21.3:1 for $90 \%$ capture ratio and $85 \%$ capacity factor. These values compare unfavorably to dispatchable scalable renewable electricity with storage, which ranges from 9:1 to 30+:1 under realistic configurations. Therefore, renewables plus storage provide a more energetically effective approach to climate mitigation than constructing CCS fossil power stations.
\end{abstract}




\section{Introduction}

Current consensus towards climate change mitigation significantly relies on carbon capture and storage (CCS) from existing and future fossil-fueled plants, recognizing it as a major component in future energy portfolios. In IEA's 2012 2DS scenario that lays out an energy system emissions trajectory consistent with $50 \%$ chance of staying below $2{ }^{\circ} \mathrm{C}$ average global temperature rise, CCS contributes around $14 \%$ of needed emissions reductions by $2050^{1}$. Integrated Assessment Models (IAMs) estimate CCS contribution from 5\% to 55\% of the total primary energy with the regressed average exceeding $20 \%$ for cumulative emissions of $1000 \mathrm{Gt} \mathrm{CO}_{2}$ or less for $66 \%$ chances of staying below the $2^{\circ} \mathrm{C}$ $\operatorname{target}^{2,3}$. These results form the basis for claims that CCS is a fundamental option for climate mitigation ${ }^{4}$. Nevertheless, general equilibrium IAMs may have their own biases that prevent them from validly considering energy portfolio mixes that diverge radically from the current one, implicitly endorsing CCS simply as an extension of the current system with added costs 5 .

Other indicators contradict the postulated ability of CCS to scale in the timeframes involved. Current deployment figures lag noticeably, with only $110 \mathrm{MW}_{\mathrm{e}}$ of power CCS installed by $2016^{6}$. Notably, China, the world's single largest emitter is expected to develop $349 \mathrm{GW}_{\mathrm{e}}$ of CCS power by 2050 in the IEA 2DS. Nevertheless, despite interest in $\mathrm{CCS}^{7}$, currently China does not have any large-scale CCS in operation and has not included CCS in the nationally determined contributions (NDC) submission to the $22^{\text {nd }}$ Conference of the Parties or in its (current) $13^{\text {th }}$ five year plan.

Worldwide, a significant gap between modeled expectations for CCS and practice emerges when comparing the $110 \mathrm{MW}_{\mathrm{e}}$ of CCS to the $227,000 \mathrm{MW}_{\mathrm{p}}$ of PV and $433,000 \mathrm{MW}_{\mathrm{p}}$ of wind cumulatively installed by $2016^{8}$ (shown in Supplementary Table 1). Of course, in itself, the fact that CCS deployment is minuscule today doesn't mean that the technology is unviable, but it raises the issue of whether it can be timely scaled-up to the level of having a cumulative adoption comparable to scalable renewable electricity (sRE). When the discrepancy between actualized CCS projects and expectations is acknowledged, it is explained by a lack of coordinated policy support and very high initial largescale demonstration project $\operatorname{costs}^{9}$ while the issue of energy losses appears to be treated as trivial ${ }^{10}$.

In contrast, we believe that properly accounting for these energy losses offers important insight in the relative performance of the two options to date and is a good predictor of their future deployment. Energy return on energy 
47 invested (EROEI) ${ }^{11,12}$ is the ratio of the energy made available to society over the energy invested in the construction, 48 operation and fuel procurement for the powerplants (see Eq. 1 in Methods). Since EROEI is a ratio, it would be 49 formally reported as X:1. For simplicity and following common practice, we omit the unitary denominator and just 50 report the numerator as EROEI. EROEI provides a measure of the relative utility of an energy technology ${ }^{13}$. Ceteris 51 paribus and with limited resources, for a given energy investment, society should prioritize the option that offers a 52 higher EROEI. As such, a worse net energy performance of CCS electricity compared to sRE may explain its 53 lackluster deployment. For greenhouse gas emission mitigation technologies of equivalent impact, the technology with 54 the better net energy performance, if chosen to replace existing conventional options, facilitates a transition trajectory 55 with higher chances to stay within emissions limits. Quantitative modeling of net energy availability indicates that the 56 EROEI of renewable energy is sufficiently large to make the transition possible within the current emission 57 constraints $^{14}$.

There exist several life cycle assessments (LCA) for CCS at the regional level ${ }^{15},{ }^{16},{ }^{17}$. A net-energy study of coal 59 liquefaction in China reported a considerable reduction of the EROEI of the process if CCS was added to the plant 60 which could lead to "extremely low, even negative" net energy returns although this is a fundamentally different 61 application to electricity generation ${ }^{18}$. A 2006 CCS and sRE life cycle comparison in the German context did not 62 evaluate net-energy performance but found that, on a lifecycle basis, CCS emissions are considerably greater 63 compared to off-shore wind farms in the North Sea and concentrated solar power (CSP) plants in North Africa per unit 64 of energy delivered ${ }^{19}$. Nevertheless, there are limited studies discussing the EROEI of CCS $^{20}$ or comparing the net energy performance of CCS and sRE.

Here, we cover this gap by presenting a general framework for consistently calculating the EROEI of CCS energy systems and of dispatchable (i.e. coupled with storage) RE resources. We use as basis prior EROEI estimates for the fuel and sRE converters and adjust for the addition of CCS and storage options respectively. This approach allows us to consistently compare CCS for electricity generation with sRE from a net-energy perspective. We estimate the EROEI of electricity from fossil-based powerplants with CCS ranging between 6.6 and 21.3 assuming that $90 \%$ of $\mathrm{CO}_{2}$ 71 is captured ratio and the plants operate at $85 \%$ capacity factors. These values compare unfavorably to the current 
EROEI of scalable renewable energy resources without storage. The EROEI of fully dispatchable RE with storage 73 ranges from 9 to 30+ for average quality PV and wind and realistic efficiency and storage fraction levels. To facilitate reading of the following sections we summarize all acronyms and symbols with their units in Supplementary Table 2.

\section{Estimating CCS energy penalties and EROEI}

The thermal powerplant energy return $\left(\mathrm{EROEI}_{\mathrm{el}}\right)$, based on its net electricity output, can be estimated using Eq. 3 in Methods. Adding CCS introduces operational and capital energy penalties, shown in Fig. 1 for an illustrative case of an amine-based CCS plant. These penalties are a result of the energy required to build and operate the four CCS process steps (separation, compression, transport, and storage). Operational energy penalties result from: $i$ ) the withdrawal of thermal energy from the steam-cycle, usually for amine regeneration, thus reducing gross electricity output and ii) from the use of electric power to operate ancillary equipment for capture and transport processes like pumps and compressors that also reduces net electricity output. Dedicated infrastructure investment for the capture system, the compressors, and the pipelines translate into additional embodied energy. While there are several alternative CCS options that differ by the type of fuel and capture process, they all introduce penalties that can be generalized into operational and capital ones. The operational energy penalty $\left(f_{\text {op }}\right)$ is the reduction in net electricity output with CCS ( $\mathrm{E}_{\mathrm{red}}$ in Fig.1) over the net electricity output without $\mathrm{CCS}\left(\mathrm{E}_{\mathrm{el}}-\mathrm{E}_{\mathrm{AUX}}\right)$ for constant fuel input. $\left.\mathrm{E}_{\mathrm{O} \& \mathrm{M}, \mathrm{CCS}}\right)$ over the energy embodied in a conventional power plant $\left(\mathrm{E}_{\mathrm{CAP}}+\mathrm{E}_{\mathrm{O} \& \mathrm{M}}\right)$ at constant fuel input. reference to the EROEI ${ }_{\mathrm{el}}$ of the non-CCS system when the value of these penalties is known. The values of the penalties depend on the concentration of the $\mathrm{CO}_{2}$ in the flue-gas stream that is process and fuel dependent, the capture ratio $(C R)$, i.e. the ratio of the $\mathrm{CO}_{2}$ that is captured from the flue-gas stream, the fuel type, and the power generation and capture processes ${ }^{21}$. Once a plant is configured, the $f_{\text {cap }}$ can be estimated using a detailed process-based LCA ${ }^{22}$ or through proxy use of environmentally-extended input-output analysis ${ }^{23}$. 


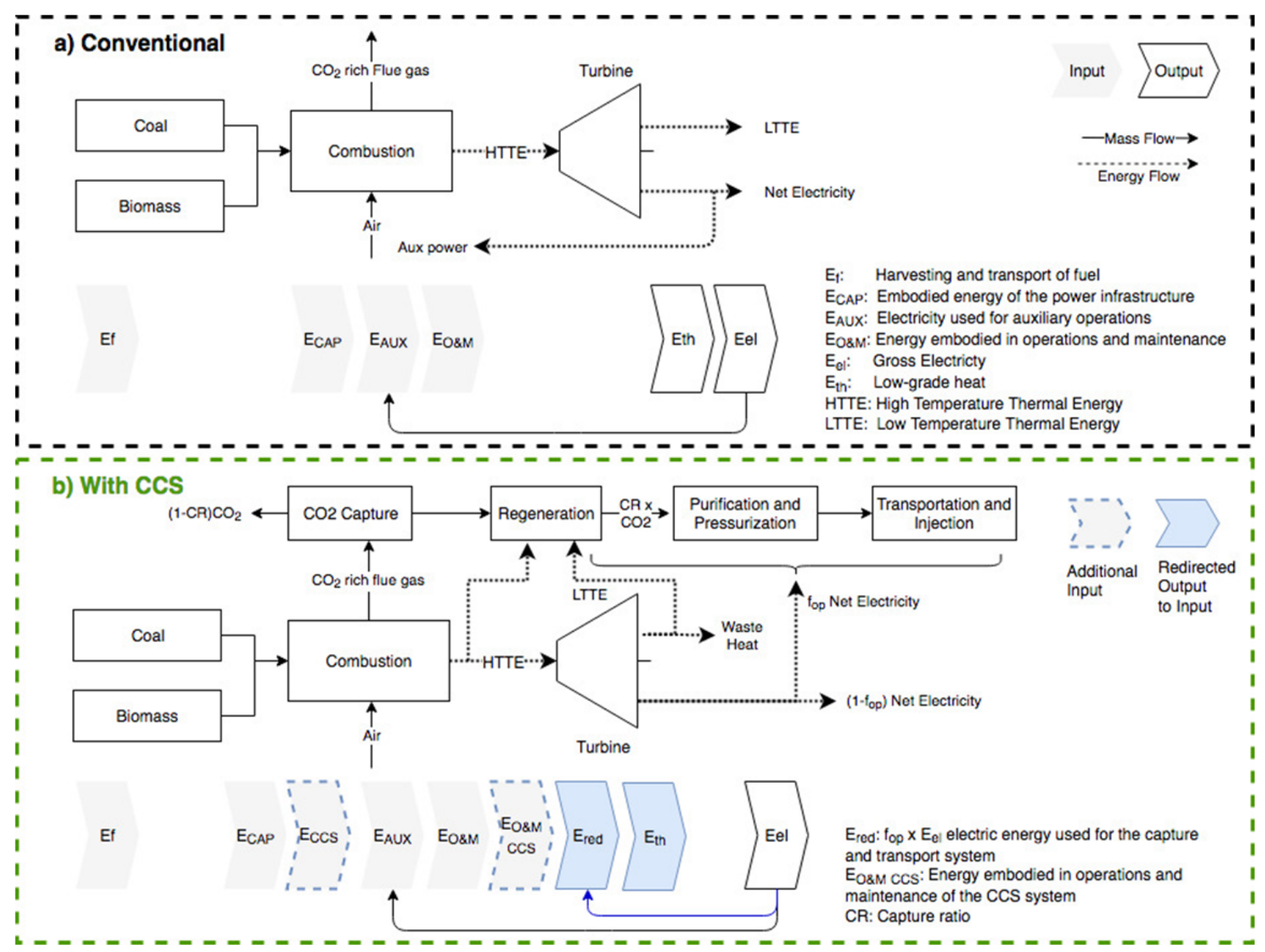

Figure 1 Difference in process mass and energy flow between conventional powerplant and one with carbon capture and sequestration. The diagrams show the mass flow for a conventional powerplant (a) and one with post-combustion CCS (b) of fuel, air and CO2 (solid lines) and the energy flows (dotted lines) in both configurations emphasizing the changes. CCS powerplants redirect energy flows utilizing high and low temperature steam and electricity from the turbine to operate the capture and transport of $\mathrm{CO}_{2}$ from the fuel combustion flue gases. They also require additional embodied energy inputs for the construction and operation of the CCS-related equipment as additional energy investment streams.

Significant progress has been achieved in mitigating operational penalties; for example the energy needed for solvent regeneration has been halved from $450 \mathrm{kWh} / \mathrm{tCO}_{2}$ in 2001 to $200 \mathrm{kWh} / \mathrm{tCO}_{2}$ in $2012^{24}$. Nevertheless, the operational energy penalty for a complete CCS cycle remains significant. Applying first principles to a pulverized coal (PC) system, the absolute lower bound for $f_{o p}$ was estimated at $11 \%$ while $29 \%$ is considered a reasonable target for $90 \% C R^{25}$. For consistency and broad technology coverage we rely on detailed process simulations ${ }^{26}$ which for $90 \%$ $C R$ indicate an average $f_{o p}$ of $28.3 \%$ for pulverized coal (PC), $21.3 \%$ for coal gasification combined cycle (IGCC) and 14.7\% for natural gas combined cycle (NGCC) (see Table 1 and Supplementary Table 3). The optimal energy penalty 
111 per $\mathrm{kg}$ of $\mathrm{CO}_{2}$ for pulverized coal plants is achieved at $C R$ between $65 \%$ and $80 \%{ }^{27}$ - though most designs aim for the

112 higher practical $C R$ of $90 \%$. Although higher capture rates are technically possible ${ }^{28}$ they have not yet been introduced

113 in planned designs. We model the effect of different capture ratios $(C R)$ on $f_{o p}$ using the relationship shown in

114 Supplementary Figure $1^{27}$. Finally, once captured $\mathrm{CO}_{2}$, must be purified to avoid two-phase flow problems and 115 compressed as a supercritical fluid transported by pipeline to the storage site. Indicatively, a $\mathrm{CO}_{2}$ flow of about $1.5 \mathrm{Mt}$ 116 per year, produced from a baseload 530MW natural gas combined cycle (NGCC) plant, requires compression power of 117 about $23 \mathrm{MW}$ or $4.3 \%$ of its output ${ }^{29}$. For distances greater than $100 \mathrm{~km}$, this becomes insufficient and repressurization stations would be needed along the way. In addition to these costs, monitoring of the injection site needs to be included as an operational investment.

Table 1 Normalized Detailed Performance Characteristics of Coal and Natural Gas Plants with and without CCS. The table shows the detailed simulated characteristics and lifetime energy flows of fossil powerplants for 90\% Capture Rates, 85\% and 55\% Capacity Factor, and $80 \mathrm{~km}$ pipeline to injection. These are used to calculate energy penalties and the corresponding EROEIs based on Eq. 1 and confirming Eq. 6 in Methods. (Based on NETL simulations ${ }^{26}$ and author calculations)

\begin{tabular}{|c|c|c|c|c|c|c|c|c|c|c|c|c|c|}
\hline \multirow{2}{*}{\multicolumn{2}{|c|}{ Case number }} & \multicolumn{6}{|c|}{$\begin{array}{l}\text { Coal Integrated Gasification Combined Cycle } \\
\text { (Based on NETL Exhibit 3-101 and normalized for coal flowrate } \\
=500000 \mathrm{lb} / \mathrm{hr} \text { ) }\end{array}$} & \multicolumn{4}{|c|}{$\begin{array}{c}\text { Pulverized Coal } \\
\text { (Based on NETL Exhibit 4-58 and normalized } \\
\text { for coal flowrate }=500000 \mathrm{lb} / \mathrm{hr} \text { ) }\end{array}$} & \multicolumn{2}{|c|}{$\begin{array}{l}\text { Natural Gas } \\
\text { Combined Cycle } \\
\text { (Exhibit 5-27) }\end{array}$} \\
\hline & & 1 & $\begin{array}{c}1 a \\
\text { (CCS) }\end{array}$ & 2 & $\begin{array}{c}2 a \\
\text { (CCS) }\end{array}$ & 3 & $\begin{array}{c}3 a \\
\text { (CCS) }\end{array}$ & 4 & $\begin{array}{c}4 a \\
\text { (CCS) }\end{array}$ & 5 & $\begin{array}{c}5 a \\
\text { (CCS) }\end{array}$ & 6 & $\begin{array}{c}\mathbf{6 a} \\
\text { (CCS) }\end{array}$ \\
\hline \multicolumn{2}{|r|}{ Gross Power Output $\left(\mathrm{kW}_{\mathrm{e}}\right)$} & 800,812 & 753,576 & 802,465 & 726,645 & 843,933 & 723,675 & 666,014 & 546,916 & 708,621 & 585,699 & 564,700 & 511,000 \\
\hline \multicolumn{2}{|c|}{ Aux Power Requirement $\left(\mathrm{kW}_{\mathrm{e}}\right)$} & 134,665 & 195,837 & 122,989 & 196,288 & 123,693 & 189,720 & 37,245 & 99,790 & 37,128 & 99,705 & 9,620 & 37,430 \\
\hline \multicolumn{2}{|r|}{ Net Power Output $\left(\mathrm{kW}_{\mathrm{e}}\right)$} & 666,148 & 557,739 & 679,475 & 530,357 & 720,240 & 533,955 & 628,770 & 447,126 & 671,493 & 485,994 & 555,080 & 473,570 \\
\hline \multicolumn{2}{|c|}{ Net Plant HHV Efficiency (\%) } & $39.0 \%$ & $32.6 \%$ & $39.7 \%$ & $31.0 \%$ & $42.1 \%$ & $31.2 \%$ & $36.8 \%$ & $26.2 \%$ & $39.3 \%$ & $28.4 \%$ & $50.2 \%$ & $42.8 \%$ \\
\hline \multirow{2}{*}{\multicolumn{2}{|c|}{$\begin{array}{l}\text { Plant Overnight Unit Cost } \\
(2007 \$ / \mathrm{kW}) \\
\text { Total Plant Costs (Millon\$) }\end{array}$}} & 1,987 & 2,711 & 1,913 & 2,817 & 2,217 & 3,181 & 1,622 & 2,942 & 1,647 & 2,913 & 584 & 1,226 \\
\hline & & 1,591 & 2,043 & 1,535 & 2,047 & 1,871 & 2,302 & 1,080 & 1,609 & 1,167 & 1,706 & 330 & 626 \\
\hline \multirow{8}{*}{ 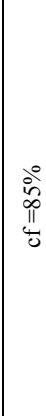 } & $\mathrm{E}_{\text {out }}(\mathrm{GWh})$ & 178,885 & 168,334 & 179,255 & 162,318 & 188,518 & 161,655 & 148,774 & 122,170 & 158,292 & 130,833 & 126,143 & 114,147 \\
\hline & $\mathrm{E}_{\text {cap-ccs }}(\mathrm{GWh})$ & & 688 & & 780 & & 657 & & 806 & & 821 & & 452 \\
\hline & $\mathrm{E}_{\text {cap }}(\mathrm{GWh})$ & 2,425 & 2,425 & 2,339 & 2,339 & 2,851 & 2,851 & 1,646 & 1,646 & 1,778 & 1,778 & 503 & 503 \\
\hline & $\mathrm{E}_{0 \& M}$ & 2,910 & 3,736 & 2,807 & 3,743 & 3,421 & 4,209 & 1,975 & 2,942 & 2,134 & 3,120 & 603 & 1,146 \\
\hline & $\mathrm{E}_{\mathrm{f}}(\mathrm{GWh})$ & 7,908 & 7,908 & 7,785 & 7,785 & 7,720 & 7,720 & 6,970 & 6,970 & 6,944 & 6,944 & 2,888 & 2,888 \\
\hline & Fuel EROEI ${ }_{\text {th }}$ & 58 & & 58 & & 58 & & 58 & & 58 & & 87 & \\
\hline & EROEI $_{\text {el }}$ (Eq. 1\&6 ) & 11.2 & 8.4 & 11.7 & 8.1 & 11.5 & 7.7 & 13.3 & 8.1 & 13.8 & 8.6 & 31.0 & 21.2 \\
\hline & R (from Eq. 6 ) & & 1.48 & & 1.51 & & 1.23 & & 1.92 & & 1.77 & & 2.61 \\
\hline \multirow{6}{*}{ 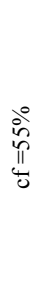 } & $\mathrm{E}_{\text {out }}(\mathrm{GWh})$ & 115,749 & 108,922 & 115,988 & 105,029 & 121,982 & 104,600 & 96,266 & 79,051 & 102,424 & 84,657 & 81,622 & 73,860 \\
\hline & $\mathrm{E}_{\text {cap-ccs }}(\mathrm{GWh})$ & & 688 & & 780 & & 657 & & 806 & & 821 & & 452 \\
\hline & $\mathrm{E}_{\text {cap }}(\mathrm{GWh})$ & 2,425 & 2,425 & 2,339 & 2,339 & 2,851 & 2,851 & 1,646 & 1,646 & 1,778 & 1,778 & 503 & 503 \\
\hline & $\mathrm{E}_{\mathrm{O \& M}}$ & 2,910 & 3,736 & 2,807 & 3,743 & 3,421 & 4,209 & 1,975 & 2,942 & 2,134 & 3,120 & 603 & 1,146 \\
\hline & $\mathrm{E}_{\mathrm{f}}(\mathrm{GWh})$ & 5,117 & 5,117 & 5,037 & 5,037 & 4,996 & 4,996 & 4,510 & 4,510 & 4,493 & 4,493 & 1,869 & 1,869 \\
\hline & Fuel EROEI $\mathrm{th}_{\text {th }}$ & 58 & & 58 & & 58 & & 58 & & 58 & & 87 & \\
\hline
\end{tabular}




\begin{tabular}{|c|c|c|c|c|c|c|c|c|c|c|c|c|}
\hline EROEI $_{\mathrm{el}}($ Eq. 1\&6) & 9.2 & 6.7 & 9.6 & 6.4 & 9.2 & 6.1 & 11.2 & 6.5 & 11.6 & 6.9 & 27.0 & 17.3 \\
\hline R (from Eq. 6 ) & & 0.96 & & 0.98 & & 0.80 & & 1.25 & & 1.15 & & 1.69 \\
\hline$f_{o p}$ & & $16.3 \%$ & & $21.9 \%$ & & $25.9 \%$ & & $28.9 \%$ & & $27.6 \%$ & & $14.7 \%$ \\
\hline$f_{\text {cap }}$ & & $28.4 \%$ & & $33.3 \%$ & & $23.0 \%$ & & $48.9 \%$ & & $46.2 \%$ & & $90.0 \%$ \\
\hline
\end{tabular}

125

126

127

128

129

130

131

132

133

134

135

136

137

138

139

140

141

The capacity factor $(c f)$, another parameter that significantly influences EROEI $_{\mathrm{el}}$ varies widely as shown in Supplementary Figure 2. Due to low gas prices, $c f$ for US coal plants declined over the period 2005-2015 from a mean of $62 \%$ to below $50 \%$, with an attendant rise for gas $c f$. While it could be assumed that CCS-enabled plants would tend to have higher capacity factors (to justify the investment cost), the increasingly lower cost of $\operatorname{sRE}^{30}$ will constrain dispatchable fossil powerplants to peaker duty thus tending to lower their $c f$.

In order to assess the influence of these set of factors we conduct a parametric analysis using realistic ranges for their values constructed from the max and minimum reported estimates in the literature as summarized in Supplementary Table 3. Figure 2 shows the relationship of the EROEI $\mathrm{CCS}_{\mathrm{C}}$ calculated using Eq. 6 in Methods under realistic ranges of operational energy penalty $f_{o p}$ and capital energy penalty $f_{c a p}$ for each thermal CCS technology. We show two representative values for capture ratios (CR) $60 \%$ and $90 \%$, capacity factors (cf) $55 \%$ and $85 \%$, and the correspondent variable (fuel) to capital and fixed operating costs ratio (R). These values are shown for a base $\mathrm{EROEI}_{\mathrm{el}}$ estimated from the upper range value of the $\mathrm{EROEI}_{\mathrm{th}}$ of the fuel (58 for coal and 87 for gas). In order to complete the analysis we also vary EROEI $_{\text {th }}$ within the reported estimates (see Methods) to create a comprehensive boundary of feasible EROEI $\mathrm{CCS}_{\mathrm{S}}$ for each technology. This is used to generate the trapezoidal profiles in Figure 4. 


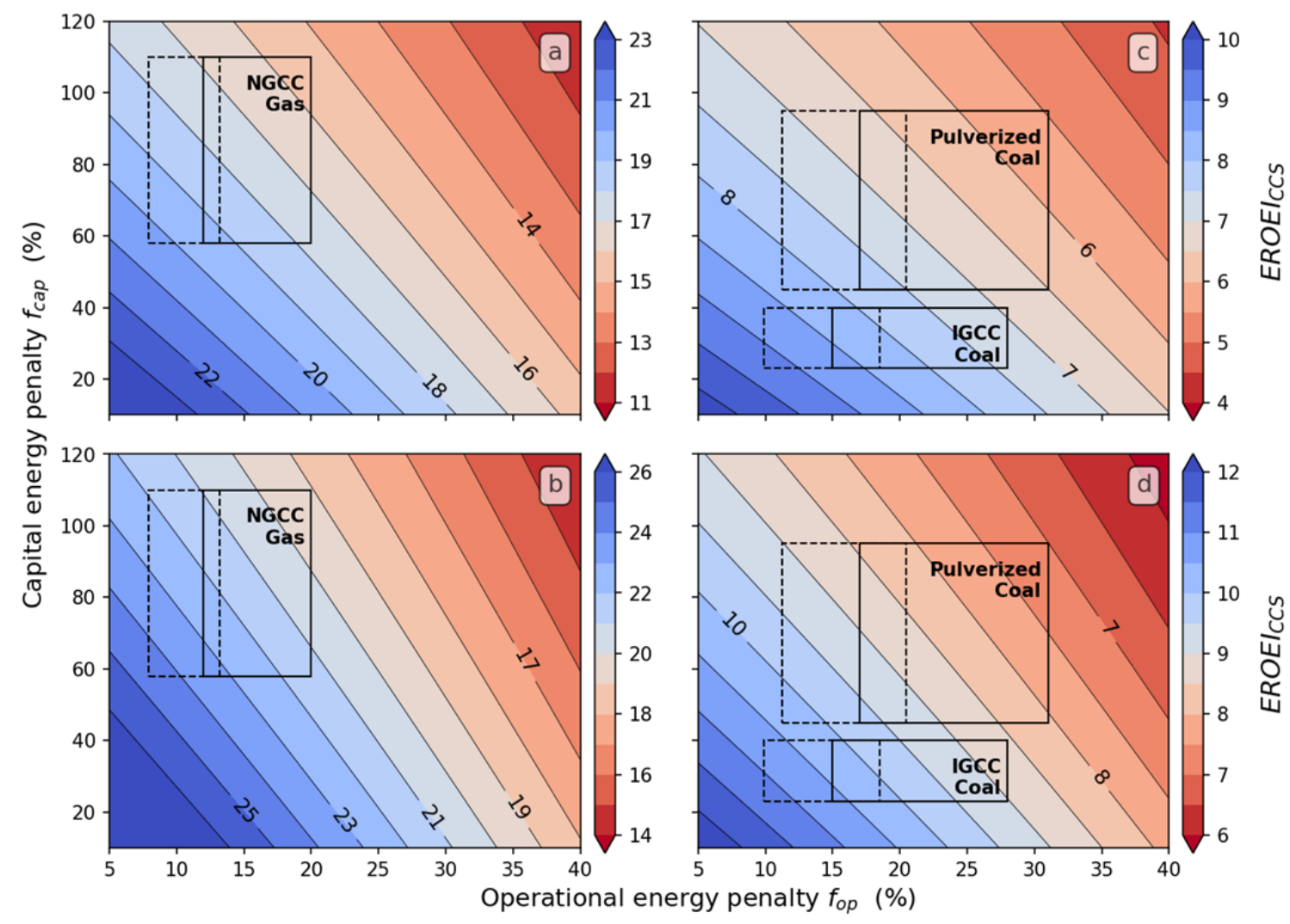

Figure 2 Energy Return on Energy Invested for coal and gas powerplants under a range of CCS energy penalties. The rectangles in the contour plots represent the EROEI $I_{\text {l }}$ for wide capital energy penalty $\left(f_{\text {cap }}\right)$ and operational energy penalty $\left(f_{\text {op }}\right)$ range for each technology for a capture ratio $C R=90$ (solid) and CR=60 (dashed). Natural Gas Combined Cycle (NGCC) assumes a fuel EROEI th $=87$. Coal pathways assume a fuel EROEI $_{\text {th }}=58$ for both the pulverized coal and the integrated gasification combined cycle (IGCC). Capacity factors (CF) shown are for $55 \%(a, c)$ and $85 \%(b, d)$. We represent the minimum and maximum encountered EROEI $I_{C S}$ values in each of these rectangles as extent edges

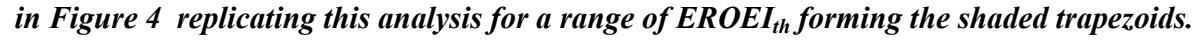

\section{EROEI Comparison of Dispatchable sRE and CCS}

For the case of sRE, EROEI depends both on the energy costs to build the plant but also on the resource quality of the area the system is installed. A meta-analysis based on 2011 data harmonized the inputs of several assessments and found that the average EROEI of PV at the inverter output ranges from 8.7 for mono-Si to 34.2 for CdTe for average insolation $\left(1700 \mathrm{kWh} / \mathrm{m}^{2}\right)^{31}$, while an analysis using more recent data of ground-mounted systems estimated a range of 25-48 for moderate and 34-65 for high insolation ${ }^{32}$. However, these values represent primary energy EROEI and should be adjusted into EROEI $_{\mathrm{el}}$ for consistency with Section 2. Multiplying with 0.35 , the same factor used in ref. ${ }^{32}$ to adjust electricity to primary energy, we get current EROEI $_{\mathrm{el}}$ ranges of 9-17 and 12-23 correspondingly. While there is 
some controversy on the PV EROEI with some studies finding lower values, a detailed response confirmed a value of 9.7 in 2016 for Switzerland's low to moderate insolation ${ }^{33}$. Given the steep learning and scale economies curves, a normalization study demonstrated the importance of using the latest information for accurately representing the stateof-the-art ${ }^{34}$. Using the historical learning curve, $\mathrm{EROEI}_{\mathrm{el}}$ for $\mathrm{PV}$ is expected to range between 20 to 40 in areas of moderately good insolation once cumulative PV capacity reaches $1.3 \mathrm{TW}^{35}$ which should happen by 2022 at current growth rates. For wind energy, similar meta-analyses found normalized EROEI $I_{e l}$ in the 20-60 range for large turbines, with several studies reporting values over $100^{36,},{ }^{37}, 38$. However, the maximum global capacity of wind farms with EROEI $_{\text {el }}$ higher than 10 may be limited to $31 \mathrm{TW}^{39}$ constrained by the availability of high-quality locations. In summary, the two RE technologies that offer the highest scaling potential, solar PV and wind both exhibit $\mathrm{EROEI}_{\mathrm{el}}$ greater than 10 even when installed in moderate resource quality areas.

An argument often raised against sRE resources is their variability and inability to be dispatched on demand ${ }^{40}$. At current adoption levels (less than $20 \%$ contribution), variable renewable electricity is integrated directly into the electricity grid without the need for deploying significant additional storage simply by utilizing the extant abilities of the power system to modulate supply and demand. Such facilities include utilizing electricity trade and long-distance transmission lines ${ }^{41}$, dispatchable and flexible powerplants (mostly hydro and gas), existing low-cost storage options like pumped-hydro, and demand response through wholesale electricity markets that may include curtailment ${ }^{42}$. At higher adoption rates, integration will become increasingly challenging ${ }^{43}$ but manageable by using storage more extensively ${ }^{44}$. Therefore, in order to compare fossils and renewables on an equal basis, we account for the use of energy storage systems that can make them fully dispatchable ${ }^{45}$.

To do this on a net-energy basis, we use the energy-stored-on-energy-invested (ESOI) (Eq. S8) ${ }^{46}$, the storage fraction $(\varphi)$, roundtrip efficiency $(\eta)$, and any potential curtailment $(k)$ to estimate the $\mathrm{EROEI}_{\text {disp }}$ (for dispatchable RE electricity) of the combined generation plus storage system for a combination of sources and storage options as shown in Eq. S11. This approach is agnostic to the storage medium and since it assumes electricity to electricity conversions, it broadly satisfies ancillary and grid-balancing requirements ${ }^{47}$. Figure 3 visualizes the relationship of EROEI $_{\mathrm{el}}$ to $\mathrm{EROEI}_{\text {disp }}$ for different storage types and a range of base $\mathrm{EROEI}_{\mathrm{el}}$ that covers that reported for the sRE spectrum. The 
183 high-end of storage fraction of $35 \%$ means that more than a third of the produced energy is stored. A high ESOI and

184 high roundtrip efficiency, typical of pumped hydro systems (d) has limited impact on EROEI $_{\text {disp }}$ even for high storage 185 fractions. Low ESOIs with high efficiency, typical of batteries (a), would only be reasonable for limited ESOIs of 10\% or less. Medium ESOIs with low efficiencies, typical of large-scale power to hydrogen (P2H) (c) exhibit more 187 manageable impacts as a $\varphi$ of $30 \%$ drops EROEI $_{\text {disp }}$ by less than $25 \%$.
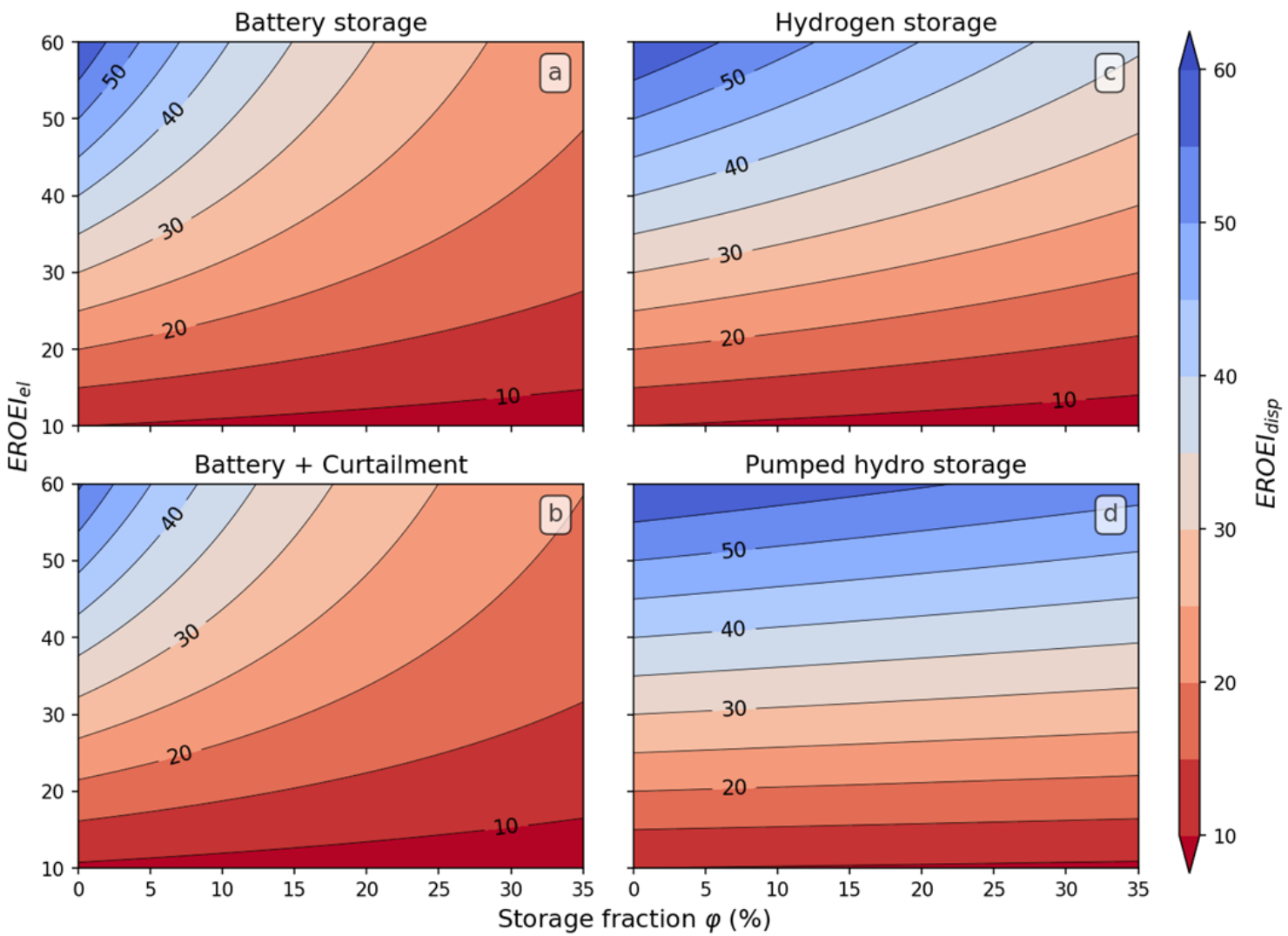

Figure 3 Energy Return on Energy Invested contours for scalable dispatchable renewables for a range of energy storage configurations.

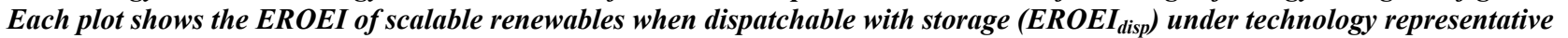
configurations of energy stored on invested (ESOI) and roundtrip efficiencies $\eta$, across a range of EROEI $I_{\text {el }}$ values: battery storage with (b) and without (a) curtailment, hydrogen (c) and pumped hydro (d) storage (both uncurtailed). Battery storage assumed ESOI=11 and $\eta=83 \%$ for (a), and additional curtailment ratio of $k=7 \%$ in (b). Hydorgen assumed an ESOI of 24 and $\eta=30 \%$ (c), and pumped hydro ESOI of 249 and $\eta=80 \%$ (d). We represent the minimum and maximum encountered EROEI ${ }_{\text {disp }}$ values in each of these rectangles as extent edges in Figure 4 creating the shaded ranges for renewables.

In order to specifically assess the impact of the critical parameters and compare them to the performance of renewable systems, we also visually present them across the plausible ranges for the different technology options. 
Figure 4 summarizes these results and compares the estimates for the $\mathrm{EROEI}_{\mathrm{CCS}}$ and $\mathrm{EROEI}_{\mathrm{disp}}$ under a range of 201 reported values by extending and merging Figures 2 and 3.

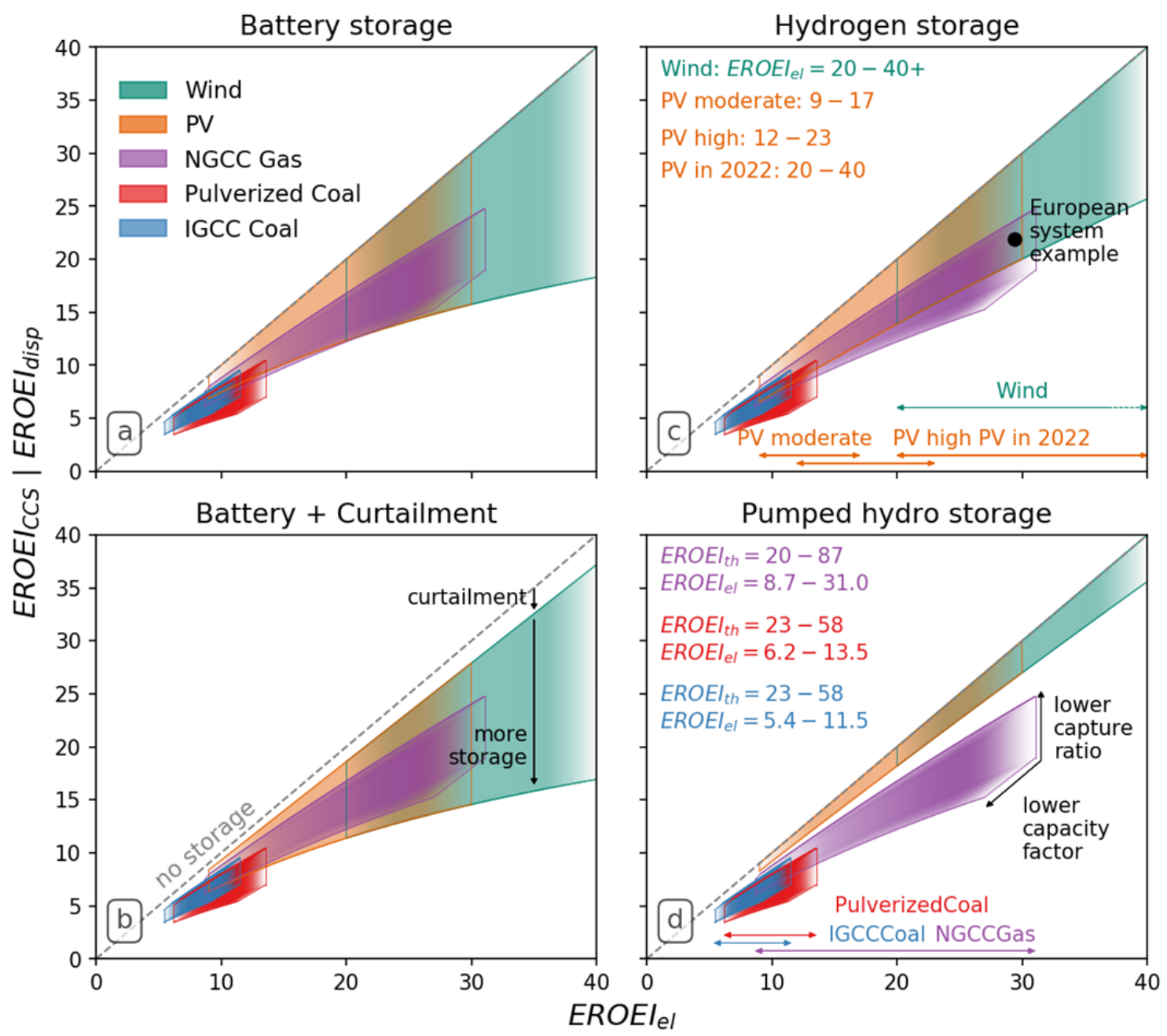

Figure 4 Comparison of adjusted Energy Return on Energy Invested for carbon capture and dispatchable renewables with energy storage. Shaded areas represent the extents of adjusted EROEIs by taking the minimum and maximum values of each individual contour plot in

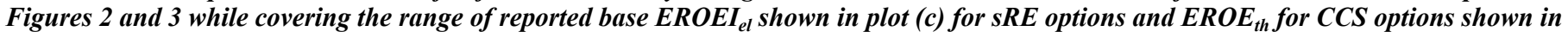
plot (d). The energy storage configurations maintain their parameters presented in Figure 3.The European system example refers to the

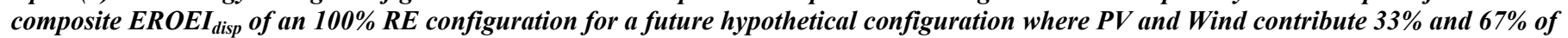
SRE supply, they are $2.1 \%$ curtailed, and stored in batteries, PHS and P2H at 5.5\%, 2.6\%, and 5.5\% storage fractions respectively (see Supplementary Table 5).

212 cases. EROEI $\mathrm{CCS}_{\mathrm{S}}$ of PC and IGCC is inferior to practically any moderate or higher quality sRE configuration, and only 213 the best $\mathrm{PC}_{\mathrm{CCS}}$ compares to the lower-end sRE resources with high storage fractions and low ESOI (Fig. 4b and 4c).

214 Nevertheless, $\mathrm{NGCC}_{\mathrm{CCS}}$ becomes competitive especially for lower capture ratios and the higher range of EROEI $\mathrm{E}_{\mathrm{th}}$. We 
examine indicative limit cases of these relationships in detail in Supplementary Table 4 for CCS plants with $85 \%$ cf

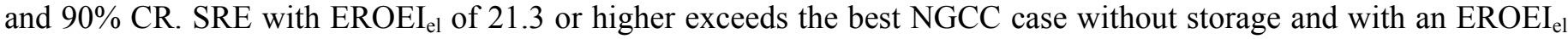
217 of 30 they can provide $16 \%$ storage fraction $(\varphi)$ in batteries and $29.9 \%$ in $\mathrm{P} 2 \mathrm{H}$. If they are stored in PHS, then 218 EROEI $_{\mathrm{el}}$ of 23.5 suffices to reach $\varphi$ of $35 \%$. These EROEI $_{\mathrm{el}}$ values are available to moderate wind and good solar 219 resources. The medium case of NGCC will be matched by an $\mathrm{EROEI}_{\mathrm{el}}$ of 20 stored at $\varphi$ of $16.5 \%$.

220 Since, the better NGCC $_{\mathrm{CCS}}$ becomes competitive with battery-stored, medium quality sRE for storage fractions 221 higher than $20 \%$ and low ESOIs (Fig. 4a,b,c) it would be important to examine their likelihood under high sRE penetration. Storage factions are not explicitly reported in current studies. The ratio of energy storage capacity over total demanded is reported and a recent review indicates values ranging from $1 \%$ to $6 \%$ for $80 \%$ RE penetration and up to $14 \%$ for $100 \%$ penetration ${ }^{48}$ consistent with a range between $10-20 \%$ by global region based on an hourly model of an $100 \%$ RE trade-connected energy system ${ }^{49}$. Such a system would utilize a portfolio of batteries, thermal, $\mathrm{P} 2 \mathrm{H}$ and mechanical (pumped-hydro and compressed-air) storage systems with different sizes and utilization patterns - i.e. batteries for multiple hourly/daily cycles, P2H for seasonal storage with 3-5 cycles, and mechanical with daily/weekly cycles. The exact composition would be system specific but the EROEI $\mathrm{disp}_{\text {of }}$ any combination can be estimated using Eq. 11 in Methods. Notably, we calculate a portfolio EROEI disp $_{\text {of }} 21.9$ (Fig. 4c) for a European 100\% RE scenario (described in detail in Methods and Supplementary Table 5) that is on par with the best NGCC $_{\mathrm{CCS}}$ estimates but further examination exceeds our purview.

\section{Conclusions}

In summary, the net-energy losses in the fossil primary energy resources from implementing CCS in power generation systems for most current deployment of RE exceed the benefits of simply directing these resources towards building a self-sustaining renewable energy infrastructure, an approach previously termed "the sower's strategy"14. Even when RE penetrations may reach or exceed $80 \%$, there are indications that the system EROEI may be equal with the better EROEI $I_{C C S}$ without the reliance on depleting resources and the non-energetic biophysical complications discussed in the Supplementary Note 1. 
References (after 49 for the Methods section)

1. IEA. Technology Roadmap Carbon Capture and Storage. 1-63 (International Energy Agency, 2013).

2. van Vuuren, D.P. et al. Carbon budgets and energy transition pathways. Environ. Res. Lett. 11, 1-12 (2016).

3. Koelbl, B. S., van den Broek, M.A., Faaij, A.P.C. \& van Vuuren, D.P. Uncertainty in Carbon Capture and Storage (CCS) deployment projections: a cross-model comparison exercise. Climatic Change 123, 461-476 (2014).

4. Bui, M. et al. Carbon capture and storage (CCS): the way forward. Energy Environ. Sci. 3, 1-115 (2018).

5. Kaya, A., Csala, D. \& Sgouridis, S. Constant elasticity of substitution functions for energy modeling in general equilibrium integrated assessment models: a critical review and recommendations. Climatic Change 43, 225-14 (2017).

6. CSI. Carbon Capture and Sequestration Project Database MIT. 1-2 (2017).

7. ADB. Roadmap for Carbon Capture and Storage Demonstration and Deployment in the People's Republic of China. 1-88 (Asian Development Bank, 2015).

8. REN21. RENEWABLES 2016 GLOBAL STATUS REPORT. 1-272 (Renewable Energy Policy Network for the 21st Century, 2016).

9. Reiner, D.M. Learning through a portfolio of carbon capture and storage demonstration projects. Nat. Energy 1, 15011-7 (2016).

10. Sanchez, D.L. \& Kammen, D. M. A commercialization strategy for carbon-negative energy. Nat. Energy 1, 15002-4 (2016).

11. Murphy, D.J. \& Hall, C.A.S. Year in review—EROI or energy return on (energy) invested. Ann. NY Acad. Sci. 1185, 102-118 (2010).

12. Murphy, D.J., Hall, C.A.S., Dale, M. \& Cleveland, C. Order from Chaos: A Preliminary Protocol for Determining the EROI of Fuels. Sustainability 3, 1888-1907 (2011).

13. Carbajales-Dale, M., Barnhart, C.J., Brandt, A.R. \& Benson, S. M. A better currency for investing in a sustainable future. Nat. Clim. Change 4, 524-527 (2014).

14. Sgouridis, S., Csala, D. \& Bardi, U. The sower's way: quantifying the narrowing net-energy pathways to a global energy transition. Environ. Res. Lett. 11, 1-8 (2016).

15. Sathre, R., Chester, M., Cain, J. \& Masanet, E. A framework for environmental assessment of CO2 capture and storage systems. Energy 37, 540-548 (2012).

16. Modahl, I. S., Askham, C., Lyng, K.-A. \& Brekke, A. Weighting of environmental trade-offs in CCS - an LCA case study of electricity from a fossil gas power plant with post-combustion $\mathrm{CO} 2$ capture, transport and storage. Int. J. Life Cycle Ass. 17, 932-943 (2012).

17. Corsten, M., Ramirez, A., Shen, L., Koornneef, J. \& Faaij, A. Environmental impact assessment of CCS chains - Lessons learned and limitations from LCA literature. Int. J. Greenh. Gas Con. 13, 5971 (2013).

18. Kong, Y. et al. EROI Analysis for Direct Coal Liquefaction without and with CCS: The Case of the Shenhua DCL Project in China. Energies 8, 786-807 (2015).

19. Viebahn, P. et al. Comparison of carbon capture and storage with renewable energy technologies regarding structural, economic, and ecological aspects in Germany. Int. J. Greenh. Gas Con. 1, 121133 (2007).

20. King, L.C. \& van den Bergh, J.C.J.M. Implications of net energy-return-on-investment for a lowcarbon energy transition. Nat. Energy 3, 334-340 (2018). 
21. Khalilpour, R. \& Abbas, A. HEN optimization for efficient retrofitting of coal-fired power plants with post-combustion carbon capture. Int. J. Greenh. Gas Con. 5, 189-199 (2011).

22. Schreiber, A., Zapp, P. \& Marx, J. Meta-Analysis of Life Cycle Assessment Studies on Electricity Generation with Carbon Capture and Storage. J. Ind. Ecol. 16, S155-S168 (2012).

23. Matthews, H.S. \& Small, M.J. Extending the Boundaries of Life Cycle Assessment through Environmental Economic Input Output Models. J. Ind. Ecol. 4, 7-10 (2000).

24. Boot-Handford, M.E. et al. Carbon capture and storage update. Energy Environ. Sci. 7, 130-189 (2014).

25. House, K.Z., Harvey, C.F., Aziz, M.J. \& Schrag, D. P. The energy penalty of post-combustion CO2 capture \& storage and its implications for retrofitting the U.S. installed base. Energy Environ. Sci. 2, 193 (2009).

26. NETL. Cost and Performance Comparison Baseline for Fossil Energy Power Plants. 1-626 (National Energy Technology Laboratory, 2013).

27. Sanpasertparnich, T., Idem, R., Bolea, I., deMontigny, D. \& Tontiwachwuthikul, P. Integration of post-combustion capture and storage into a pulverized coal-fired power plant. Int. J. Greenh. Gas Con. 4, 499-510 (2010).

28. Abu-Zahra, M.R.M., Schneiders, L.H.J., Niederer, J.P.M., Feron, P.H.M. \& Versteeg, G.F. CO2 capture from power plants. Int. J. Greenh. Gas Con. 1, 37-46 (2007).

29. El-Suleiman, A., Anosike, N. \& Pilidis, P. A Preliminary Assessment of the Initial Compression Power Requirement in CO2 Pipeline 'Carbon Capture and Storage (CCS) Technologies'.

Technologies 4, 15-9 (2016).

30. Apostoleris, H., Sgouridis, S., Stefancich, M. \& Chiesa, M. Evaluating the factors that led to lowpriced solar electricity projects in the Middle East. Nat. Energy 11, 094009-6 (2018).

31. Bhandari, K.P., Collier, J. M., Ellingson, R.J. \& Apul, D.S. Renewable and Sustainable Energy Reviews. Renew. Sust. Energ. Rev. 47, 133-141 (2015).

32. Leccisi, E., Raugei, M. \& Fthenakis, V. The Energy and Environmental Performance of GroundMounted Photovoltaic Systems-A Timely Update. Energies 9, 622-13 (2016).

33. Raugei, M. et al. Energy Return on Energy Invested (ERoEI) for photovoltaic solar systems in regions of moderate insolation_A comprehensive response. Energ. Policy 102, 377-384 (2017).

34. Koppelaar, R.H.E.M. Solar-PV energy payback and net energy_ Meta-assessment of study quality, reproducibility, and results harmonization. Renew. Sust. Energ. Rev. 1-15 (2016).

35. Görig, M. \& Breyer, C. Energy learning curves of PV systems. Environ. Prog. Sustainable Energy 35, 914-923 (2016).

36. Davidsson, S., Höök, M. \& Wall, G. A review of life cycle assessments on wind energy systems. Int $J$ Life Cycle Assess 17, 729-742 (2012).

37. Dale, M. A Comparative Analysis of Energy Costs of Photovoltaic, Solar Thermal, and Wind Electricity Generation Technologies. Appl. Sci. 3, 325-337 (2013).

38. Kubiszewski, I., Cleveland, C.J. \& Endres, P.K. Meta-analysis of net energy return for wind power systems. Renew. Energ. 35, 218-225 (2010).

39. Dupont, E., Koppelaar, R. \& Jeanmart, H. Global available wind energy with physical and energy return on investment constraints. Appl. Energ. 209, 322-338 (2017).

40. Hirth, L., Ueckerdt, F. \& Edenhofer, O. Integration costs revisited e An economic framework for wind and solar variability. Renew. Energ. 74, 925-939 (2015).

41. Jaehnert, S., Wolfgang, O., Farahmand, H., Völler, S. \& Huertas-Hernando, D. Transmission expansion planning in Northern Europe in 2030-Methodology and analyses. Energ. Policy 61, 125 139 (2013). 
42. Jacobsen, H.K. \& Schröder, S.T. Curtailment of renewable generation economic optimality and incentives. Energ. Policy 49, 663-675 (2012).

43. Ueckerdt, F., Brecha, R. \& Luderer, G. Analyzing major challenges of wind and solar variability in power systems. Renew. Energ. 81, 1-10 (2015).

44. Frew, B.A., Becker, S., Dvorak, M.J., Andresen, G.B. \& Jacobson, M.Z. Flexibility mechanisms and pathways to a highly renewable US electricity future. Energy 101, 65-78 (2016).

45. Gils, H.C., Scholz, Y., Pregger, T., de Tena, D. L. \& Heide, D. Integrated modelling of variable renewable energy-based power supply in Europe. Energy 123, 173-188 (2017).

46. Barnhart, C.J., Dale, M., Brandt, A.R. \& Benson, S.M. The energetic implications of curtailing versus storing solar- and wind-generated electricity. Energy Environ. Sci. 6, 2804 (2013).

47. Koller, M., Borsche, T., Ulbig, A. \& Andersson, G. Review of grid applications with the Zurich 1MW battery energy storage system. Electr. Pow. Syst. Res. 120, 128-135 (2015).

48. Blanco, H. \& Faaij, A. A review at the role of storage in energy systems with a focus on Power to Gas and long-term storage. Renew. Sust. Energ. Rev. 81, 1049-1086 (2018).

49. Breyer, C. et al. On the role of solar photovoltaics in global energy transition scenarios. Prog. Photovolt: Res. Appl. 6, 545-20 (2017).

50. Hagens, N.J. TOWARDS AN APPLIED NET ENERGY FRAMEWORK. 1-184 (2010).

51. Zhang, Y. \& Colosi, L.M. Practical ambiguities during calculation of energy ratios and their impacts on life cycle assessment calculations. Energ. Policy 57, 630-633 (2013).

52. Metz, B., Davidson, O., De Coninck, H., Loos, M. \& Meyer, L. IPCC special report on carbon dioxide capture and storage. (2005).

53. Mokhtar, M. et al. Solar-assisted Post-combustion Carbon Capture feasibility study. Appl. Energ. 92, 668-676 (2012).

54. Harkin, T., Hoadley, A. \& Hooper, B. Reducing the energy penalty of $\mathrm{CO} 2$ capture and compression using pinch analysis. J. Clean. Prod. 18, 857-866 (2010).

55. CMU-GDI. Economic Input-Output Life Cycle Assessment EIO-LCA: Free, Fast, Easy Life Cycle Assessment. (2018).

56. BLS. Producer Price Index (PPI). 1-6 (2018).

57. Knoope, M.M.J., Ramírez, A. \& Faaij, A.P.C. A state-of-the-art review of techno-economic models predicting the costs of CO2 pipeline transport. Int. J. Greenh. Gas Con. 16, 241-270 (2013).

58. Chandel, M. K., Pratson, L. F. \& Williams, E. Potential economies of scale in CO2 transport through use of a trunk pipeline. Energ. Convers. Manage. 51, 2825-2834 (2010).

59. Kolster, C., Mechleri, E., Krevor, S. \& Mac Dowell, N. The role of CO2 purification and transport networks in carbon capture and storage cost reduction. Int. J. Greenh. Gas Con. 58, 127-141 (2017).

60. Knoope, M.M.J., Ramírez, A. \& Faaij, A.P.C. The influence of uncertainty in the development of a CO2 infrastructure network. Appl. Energ. 158, 332-347 (2015).

61. Mechleri, E., Brown, S., Fennell, P.S. \& Mac Dowell, N. CO2 capture and storage (CCS) cost reduction via infrastructure right-sizing. Chem. Eng. Res. Des. 119, 130-139 (2017).

62. Freise, J. The EROI of Conventional Canadian Natural Gas Production. Sustainability 3, 2080-2104 (2011).

63. Sell, B., Murphy, D. \& Hall, C.A.S. Energy Return on Energy Invested for Tight Gas Wells in the Appalachian Basin, United States of America. Sustainability 3, 1986-2008 (2011).

64. Poisson, A. \& Hall, C. Time Series EROI for Canadian Oil and Gas. Energies 6, 5940-5959 (2013).

65. Hu, Y., Hall, C. A. S., Wang, J., Feng, L. \& Poisson, A. Energy Return on Investment (EROI) of China. Energy 54, 352-364 (2013). 
391 66. Hall, C.A.S., Lambert, J. G. \& Balogh, S. B. EROI of different fuels and the implications for society. 392 Energ. Policy 64, 141-152 (2014).

393 67. Barnhart, C.J. \& Benson, S. M. On the importance of reducing the energetic and material demands of electrical energy storage. Energy Environ. Sci. 6, 1083-10 (2013).

68. Wendel, C.H., Kazempoor, P. \& Braun, R. J. Novel electrical energy storage system based on reversible solid oxide cells: System design and operating conditions. J. Power Sources 276, 133-144 (2015).

69. Pellow, M.A., Emmott, C.J.M., Barnhart, C.J. \& Benson, S.M. Hydrogen or batteries for grid storage? A net energy analysis. Energy Environ. Sci. 8, 1938-1952 (2015). 


\section{Methods}

\section{Energy return on energy investment}

The energy return on energy investment (EROEI/ERoEI or EROI) is a measure of the ratio of available energy that a process provides $\left(\mathrm{E}_{\mathrm{out}}\right)$ over the energy that needs to be expended for that process $\left(\mathrm{E}_{\mathrm{in}}\right)$. As a physical measure, EROEI presents an alternative to monetary-based comparisons with distinct advantages ${ }^{13}$. Nevertheless, determining the EROEI of a process requires attention because it depends on the boundary of the analysis and it is specified in five accounting levels: internal energy, external energy, material energy, labor, and ancillary services of energy use ${ }^{12}$. The common accounting boundary proposed as standard ${ }^{12}$ includes the first three. The energy investment includes the capital energy investment embodied in the materials and used for the construction and eventual decommission $\left(E_{\text {cap }}\right)$, the energy needed for operating the powerplant $\left(\mathrm{E}_{\mathrm{O} \& \mathrm{M}}\right)$, and for procuring and distributing the fuel $\left(E_{f}\right)(\mathrm{Eq} .1)$.

$$
E R O E I=\frac{E_{\text {out }}}{E_{\text {in }}}=\frac{E_{\text {out }}}{E_{\text {cap }}+E_{\text {O\&M }}+E_{f}} \quad \text { Eq. } 1
$$

A subtle but important consideration in the calculation of the EROEI for chained, multi-step processes is how to handle internal energy use. Should the high-quality energy that becomes available from an upstream step but is then used in a transformation at a downstream step be considered as an input or not? In essence, choosing to ignore internal energy use omits the opportunity cost of directing that energy to other purposes ${ }^{50}$. This results in masking the overall process actual energy costs potentially overestimating its energetic performance ${ }^{51}$. While we recognize this potential weakness, we opt to assess fossil system EROEI using only the net energy outputs and without accounting for the internal energy streams. This option offers a simple energetic calculus clearly indicating how much energy needs to be invested to deliver a given amount of electricity. Moreover, for electricity generating systems, process efficiency can increase by adding internal energy exchange steps (e.g. using a combined Rankine and Brayton cycle system) as opposed to operating them individually. Considering such internal process energy flows outside the boundary, would lead to, counterintuitively, lower EROEI for the combined system. Finally, the choice of omitting internal energy streams is conservative as it provides the higher range of estimates of EROEI for CCS processes. We use this approach to develop a generalizable approach to estimate the EROEI of $\mathrm{CO}_{2}$ harvesting processes with CCS. 


\section{Power CCS Processes and Steps}

The first step of CCS, capture, is well understood and there exist a variety of technology options for carbon capture from fossil fuel combustion ${ }^{52}{ }^{24}$. In IGCC plants, pre-combustion of the carbon components through gasification of coal and a subsequent water-gas-shift reaction of the syngas leaves hydrogen for powering the gas turbine while the $\mathrm{CO}_{2}$ can be separated and captured. Post-combustion, which is the foremost currently commercialized process, separates the $\mathrm{CO}_{2}$ present in concentrations of $5-15 \%$ from the flue gases of conventional combustion systems. It is also possible to utilize oxy-fuel combustion, that is combustion with high oxygen concentration, to produce effluent gas with correspondingly high concentrations of $\mathrm{CO}_{2}$. Post-combustion processes include physical methods, such as cryogenic separation, chemical capture in solvents such as amine solutions, ionic liquids, electrochemical or plasma activation of $\mathrm{CO}_{2}$, and more. In practice, the commercially considered methods are either post-combustion separation via amine solutions or oxy-combustion although in practice the latter seems to face additional obstacles in utility-scale deployment.

The captured $\mathrm{CO}_{2}$ needs to be transported, compressed for ease of handling, via pipeline or ship to the location where it will be processed and stored. The final step involves storing the $\mathrm{CO}_{2}$ in forms expected to remain stable at least for a few centuries. Storage may be achieved by pumping the $\mathrm{CO}_{2}$ gas into an appropriate geologic formation, usually saline aquifers, depleted oil and gas reservoirs, or active oil reservoirs for enhanced oil recovery (EOR). Other proposed methods involve storage in abandoned mines, the injection of liquefied $\mathrm{CO}_{2}$ in deep ocean, and chemical sequestration, that is transforming $\mathrm{CO} 2$ into a solid product such as pure carbon or carbonates. This diversity in possible combinations of capture and storage makes a comprehensive and detailed net energy analysis of each combination impractical leading us to create a generalized CCS EROEI methodology.

\section{Energy penalties}

In the post- and pre-combustion cases, the fuel type plays a significant role on the energy requirements of the capture process. The theoretical estimates referenced in Section 2 are confirmed from the detailed simulations of several IGCC (integrated gasification combined cycle), PC, and NGCC (natural gas combined cycle) configurations 
with and without CCS, shown in Table 1. These values include the pressurization, transportation and injection components for a favorable saline aquifer injection site served by an $80 \mathrm{~km}$ pipeline. While we cannot exclude that scaled deployment and technological progress could lead to more favorable parameters for fossil/CCS power plants, current project prices are much higher (see Supplementary Note 1).

While it may be possible to mitigate fossil fuel energy penalties by integrating lower-grade heat sources like solar thermal in the plant design ${ }^{53}$ such strategies increase the capital costs and introduce an additional energy resource in the denomination indicating that the overall system $\mathrm{EROEI}_{\mathrm{el}}$ may not be improved significantly. Improvements by optimizing process integration ${ }^{54}$ at minimal additional costs are possible but do not drastically change the process energy balances.

\section{Capital Cost Penalties}

Based on the plant costs presented in Table S1, we use the US2002 producer model to estimate the energy requirements of the plant investment. Assuming that $60 \%$ of the investment is in construction (Sector \#230102: Nonresidential manufacturing structures) and $40 \%$ is in machinery (approximated by Sector \#333611:Turbine and turbine generator set units manufacturing), the energy intensity is 6.042TJ per million 2002 US dollars (US2002 428sector producer model ${ }^{55}$ ). Accounting for inflation to 2007 using the producer price index (PCU3336: PPI industry group data for Turbine and power transmission equipment manufacturing ${ }^{56}$ ) the intensity is 5.49TJ per million 2007 USD. Using this approximation, the average $f_{\text {cap }}$ estimates for the systems in Table S1 are $28 \%$ for IGCC, $48 \%$ for PC, and $90 \%$ for NGCC.

These estimates account only for short transport pipelines and compression under favorable conditions, actual values in large-scale adoption would likely be higher as a longer transportation network would be needed. Widely-used approximation models to estimate pipeline capital and operation costs can be simplistic and lead to underestimating the costs unless based on pipeline weight ${ }^{57}$. The optimal design of a complete pipeline network relies on pooling together several sources and build trunk pipelines to utilize scale economies ${ }^{58,59}$. In practice though, project costs and risks favor an incremental project-based approach with point-to-point pipeline as developments depend on future carbon price 
expectations that can be subject to significant uncertainty at the time of investment decisions. In this case, the per stored tonne cost of a point-to-point system may be anywhere from $30 \%$ to $350 \%$ higher than would be the case for an optimal network $^{60}$. Compounding the uncertainty is the level of renewable energy adoption and the concomitant reduction in the utilization of CCS fossil-fired power plants favoring a smaller size pipeline investment ${ }^{61}$. These factors suggest that initial deployment of CCS is highly unlikely to be part of a scale-optimized network and, in the absence of enforceable planning legislation, it will be difficult to reverse the trend in the future.

Given the differences in design and assumptions, we use a review study that normalized the data from several CCS studies, including the one reviewed in details in Table 1 to obtain ranges for $f_{\text {op }}$ and $f_{\text {cap }}$ shown in Table Supplementary Table 3. The ranges used in Figure 2 cover the min and max reported $f_{o p}$ and $f_{\text {cap }}$. The $f_{\text {cap }}$ in Supplementary Table 3 is approximately estimated as $f_{\text {cap }}=\frac{\left(C C S_{\text {cost }}-\text { Conventional }_{\text {cost }}\right)}{\text { Conventional }}\left(1-f_{\text {opst }}\right)$ in the absence of the detailed data used in Table 1 for all cases but the wide range coverage negates any potential shortcoming of this assumption since the range well encompasses the values of Table 1 .

\section{EROEI of fuels and thermal electricity generation systems}

In order to evaluate their relative performance, this section reviews the EROEI of the fossil options (IGCC, PC, and NGCC) together with the EROEI of dispatchable scalable RE. The EROEI of the fuel is reported separately and we denote that with the suffix th. The EROEI $\mathrm{e}_{\mathrm{e}}$, referring to the electricity output, additionally accounts for the conversion efficiency $(\eta)$, the power-plant invested energy $\left(E_{c a p}\right)$ and the operations and maintenance expenses $\left(E_{O \& M}\right)$. There is significant divergence in the literature reported EROEI $I_{\text {th }}$ for fuels. Using a monetary basis for the calculation, Freise estimates the Canadian conventional natural gas EROEI $\mathrm{th}_{\mathrm{h}}$ in 2009 as 20 from a peak of around 80 in $1970 \mathrm{~s}^{62}$. A more detailed material analysis estimated the average $\mathrm{EROEI}_{\text {th }}$ of tight gas wells drilled in Indiana in the period between 1985 and 2003 at $87^{63}$. On the other hand, a study of the combined oil and gas sector estimated a current EROEI of 11 for Canada ${ }^{64}$ and around 10 for China ${ }^{65}$. Since both these studies report the combined sectors, we do not lower the EROEI range for gas below 20. The most recent estimates for coal EROEI th $_{\text {th }}$ range from 23 to $58^{66}$ while for China coal EROEI at 24 falls on the lower end of the range ${ }^{65}$. We use these values as EROEI th $_{\text {th }}$ ranges for completing 
501 the comparative Figure 4. The general trend is that resource depletion increases the energy intensity of the extraction 502 processes and the fuel's EROEI deteriorates.

503 Figure 1 shows a schematic fossil-fuel fired coal/biomass plant along with a CCS option. This arrangement 504 shows the corresponding energy flows and the EROEI estimation after accounting for the process energy penalty 505 flows. Eq. S1 shows the conventional EROEI estimate. The energetic cost of the power-plant infrastructure is a 506 product of the installed capacity $(P)$ and the unit energy intensity $(\varepsilon)$ or embodied energy of capital per installed unit of 507 power. Operation and maintenance $\left(\mathrm{E}_{\mathrm{O \& M}}\right)$ is referenced as a share $\left(\mathrm{s}_{\mathrm{O \& M}}\right)$ of the investment cost. Over its lifetime, the 508 powerplant will generate electrical energy $\mathrm{E}_{\mathrm{el}}$ and will consume fuel with a thermal energy content $\mathrm{E}_{\text {th }}$ as shown in Eq. 509 2. From the EROEI definition the fuel procurement energy $\left(\mathrm{E}_{\mathrm{f}}\right)$ is calculated by dividing the thermal energy content $510\left(\mathrm{E}_{\mathrm{th}}\right)$ of the fuel used with its EROEI $\mathrm{th}_{\mathrm{th}}$. Expanding Eq. 1 with Eq. 2 provides the relationship of EROEI $\mathrm{I}_{\mathrm{el}}$ to cycle 511 efficiency $(\eta)$, plant-lifetime $(L)$, and capacity factor $(c f)$ that becomes independent of capacity $(P)$ (see Eq. 3).

$$
\begin{array}{cc}
E_{\text {out }}=P c f L, \text { and } E_{\text {th }}=\frac{P c f L}{\eta} & \text { Eq. } 2 \\
E R O E I_{\text {el }}=\frac{P c f L}{P \varepsilon\left(1+L S_{O \& M}\right)+P c f \frac{L}{n E R O E I_{t h}}}=\frac{c f L}{\varepsilon\left(1+L S_{O \& M}\right)+c f \frac{L}{\overline{n E R O E I_{\text {th }}}}} \quad \text { Eq. } 3
\end{array}
$$

Using Eq. S1 to include the CCS process leads to Eq. S4. The re-purposed energy flows that were previously available as an output are subtracted from the numerator (energy out) while the additional capital and operating investments for the CCS plants are added to the denominator. We can then divide Eq. 4 and Eq. 1, generalizing, for a given capture ratio $(C R)$ and assuming the same fuel input we can derive Eq. 5. Defining the reference ratio of fuel to capital and non-fuel operating energetic costs of the conventional plant as R, we can simplify Eq. 5 to Eq. 6 .

$$
\begin{aligned}
& E R O E I_{C C S}=\frac{E_{e l}\left[1-f_{o p}(C R)\right]}{E_{c a p}\left(1+f_{C A P}\right)+E_{C C S O \& M}+E_{f}}=\frac{E_{e l}\left[1-f_{o p}(C R)\right]}{E_{c a p}\left(1+f_{C A P}\right)\left(1+L s_{O \& M}\right)+E_{f}} \\
& E R O E I_{C C S}=\left[1-f_{o p}(C R)\right] \frac{E_{c a p}(1+L s)+E_{f}}{E_{c a p}\left(1+f_{c a p}\right)\left(1+L s_{O \& M}\right)+E_{f}} E R O E I_{e l} \\
& E R O E I_{C C S}=\left[1-f_{o p}(C R)\right] \frac{R+1}{R+1+f_{c a p}} E R O E I_{e l}, R=\frac{E_{f}}{E_{c a p}\left(1+L s_{O \& M}\right)}
\end{aligned}
$$




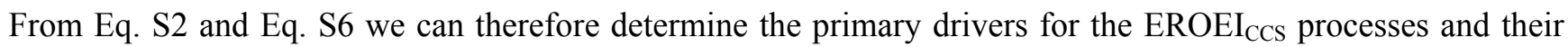
relationship to conventional. Expectedly, the EROEI $I_{C C S}$ is higher when the conventional process has a high EROEI $_{\mathrm{el}}$.

524 High capacity factors, long asset life, low O\&M costs and especially a high EROEI $_{\text {th }}$ are positively contributing 525 factors. If the capital and operating energy expenses increase as a result of less favorable injection locations, then they 526 would negatively impact the CCS EROEI. Finally, lower capture ratios, decrease both the operational and capital 527 penalties at the expense of more atmospheric carbon release and higher unit carbon costs as shown in Supplementary 528 Figure 1. Table 1 also provides the detailed estimation of the EROEI $_{\mathrm{el}}$ of six simulated conventional and CCS cases 529 demonstrating that Eq.1 and Eq. 6 are fully compatible. Since both EROEI $I_{\mathrm{el}}$ and R depend on the capacity factor 530 (graphically shown in Supplementary Figure 2 for the USA), we use these relationships to estimate $\mathrm{EROEI}_{\mathrm{CCS}}$ for a 531 continuous capacity factor range from $55 \%$ to $85 \%$ in line with Supplementary Figure 2 and populate the CCS shaded 532 regions in Figure 4.

\section{3}

\section{EROEI of Dispatchable RE}

In order to compare fossils and renewables on an equal basis for high RE adoption rates, we should account for the use of energy storage systems that can make them fully dispatchable ${ }^{45}$. Prior work developed an equation that provided an upper limit on the EROEI of the combined RE and storage system ${ }^{46}$. It assumed that storage is fully utilized to its lifetime limit and that there is no curtailment. We extend it to relax these assumptions. We use the concept of energy-stored-on-energy-invested (ESOI), for a storage fraction $(\varphi)$ and storage cycle efficiency $(\eta)$, and curtailment ratio $(\mathrm{k})$, to estimate the EROEI of the combined generation plus storage system using Eq. $7^{46}$. ESOI is defined as the ratio of energy stored under full utilization (i.e. exchaustion of designed cycles) of the storage system over the energy invested in its construction ${ }^{67}$ which is shown in Eq. 7 where $\varepsilon$ is the embodied energy as above.

$$
\text { ESOI }=\frac{C \lambda_{c} \eta D}{C \varepsilon}=\frac{\lambda_{c} \eta D}{\varepsilon}\left[\frac{k W h_{e} \text { stored }}{k W h_{e} \text { embodied }}\right] \quad \text { Eq. } 7
$$

The ESOI for storage systems depends on the number of capacity cycles $\left(\lambda_{c}\right)$, the storage efficiency $(\eta)$ and the depth of discharge (D). Storage systems that are designed for medium or longer term (weeks to months) storage like 
PHS, CAES and P2X demonstrate a large energy capacity to power ratio. Unlike short- and medium-term storage that 547 could be utilized over several hundred cycles a year, reversible P2X system cycles may see fewer than 5 storage 548 capacity cycles per year. This creates the impression of under-utilization, but these systems comprise of energetically 549 expensive power converters, i.e. power-limited charge/discharge systems with a relatively shorter lifetime (e.g. 550 electrolyzer and fuel-cell stacks) and a storage system (at this scales caverns and large tanks) exhibiting strong 551 economies of scale and long lifetimes. As a result, the actual capacity/volume of energy storage is not the limiting 552 parameter in estimating net energy performance but rather the charge/discharge power and power cycles $\left(\lambda_{\mathrm{p}}\right)$. To 553 represent this, we separate the embodied energy of the power system $\left(\varepsilon_{\mathrm{p}}\right)$ from the storage system $\left(\varepsilon_{\mathrm{s}}\right)$, a distinction that 554 is not relevant for solid batteries (in which case we consider that $\varepsilon_{\mathrm{s}}=0$ ) but can become significant for systems that 555 utilize liquids, gases or chemicals for storage modifying ESOI as in Eq. 8.

$$
\text { ESOI }=\frac{C \lambda_{c} \eta D}{P \varepsilon_{p}+C \varepsilon_{S}}=\frac{P \lambda_{p} \eta D}{P \varepsilon_{p}\left(1+\frac{C \varepsilon_{s}}{P \varepsilon_{p}}\right)}=\frac{\lambda_{p} \eta D}{\varepsilon_{p} u}\left[\frac{k W h_{e} \text { stored }}{k W h_{e} \text { embodied }}\right], u=\frac{C}{P} \frac{\varepsilon_{s}}{\varepsilon_{p}}+1
$$

Eq. 9 represents the total EROEI of the dispatchable sRE system. We allow a portfolio of energy generation (i) and energy storage $(\mathrm{j})$ types.

$$
E R O E I_{d i s p}=\frac{E_{\text {out }}-\sum_{j}\left(1-\eta_{j}\right) \varphi_{j} E_{\text {out }}-c E_{\text {out }}}{\sum_{i} E_{i n_{-} i}+\sum_{j} E_{i n_{-} j}} \forall i, j
$$

Substituting from the definition of EROEI (Eq. 1) and ESOI (Eq. 8) weighted by their fractional contribution $(\alpha)$, we get Eq. 10 which simplifies to 11 . For a single sRE system and storage system combination that is fully utilized without curtailment Eq. 11 becomes equivalent to the previously developed Eq. $12^{67}$. We note that ESOI is independent of the storage fraction and curtailment but is dependent on the roundtrip efficiency.

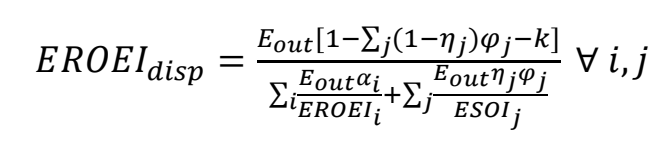

$$
E R O E I_{d i s p}=\frac{1-\sum_{j}\left(1-\eta_{j}\right) \varphi_{j}-k}{\sum_{i} \frac{\alpha_{i}}{\operatorname{EROEI}_{i}}+\sum_{j} \frac{\eta_{j} \varphi_{j}}{\overline{E S O I}_{j}}} \forall i, j
$$

$$
E R O E I_{d i s p}=\frac{1-\varphi+\eta \varphi}{\frac{1}{E R O E I_{e l}}+\frac{\eta \varphi}{E S O I}}
$$


This approach is agnostic to the storage medium and can work equally well for batteries, thermal storage, 568 pumped-hydro, and their combinations. Since it assumes electricity to electricity conversions, it satisfies all other ancillary balancing requirements. In practice as sRE become adopted the systems will progressively evolve. At the current low sRE penetration ( $<30 \%$ of total supply), there is limited to no need for storage and the network can accept the sRE without additional configuration ${ }^{48}$. SRE in this case are simply handled as negative loads (they subtract from the load curve) and the system operates by using existing flexible load followers (hydro and gas turbines) essentially reducing the fuel use of these resources. Some limited curtailment during very high SRE events becomes acceptable $(<2 \%)$. Utilization of conventional generation is reduced. As penetration increases to $30-80 \%$, storage dedicated to equalizing the sRE supply intra-day and up to a week becomes necessary. This role would be filled by batteries along with PHS and thermal storage depending on which storage type is conducive for the system's location and morphology. The "long-gaps" and load peaks that do not coincide with VRE supply would be filled by conventional generation at low utilization factors (which also implies low EROEI $\mathrm{el}_{\mathrm{l}}$ for them, cf. Eq. S3). Given the lower fuel demand, biofuels like bio-gas could also cover a sizable part of this demand. For systems where RE exceeds $80 \%$ and up to $100 \%$, peak generation will need to be supplied from a combination of biofuels and P2H or P2X storage.

One such reversible P2X proposal envisions a two-tank, closed loop system that circulates carbon as the carrier molecule through a reversible solid oxide fuel cell. In charging mode, stored $\mathrm{CO}_{2}$ and water are processed through fuel cell stacks with electricity input to generate a mix of methane, hydrogen and carbon monoxide that is stored under pressure. The reverse process takes place in discharging mode with electricity as output estimating a $70 \%$ round-trip efficiency at intermediate cell temperatures $\left(680^{\circ} \mathrm{C}\right)^{68}$. A similar open cycle process using ammonia as the hydrogen carrier would also have low storage costs would require nitrogen air separation and a single reservoir.

A detailed analysis of different levels of RE penetration is system and context specific. The ESOEI of different options is practically bimodal with batteries exhibiting low values, while pumped-hydro and compressed-air high values $^{46}$. We use the values reported by Pellow et al. (Table 2 in ref. ${ }^{69}$ ). Since these were estimated with the embodied energy transformed into electric - we revise them to be consistent with our use of primary energy in the EROEI/ESOI denominator by multiplying by 0.3 - the same factor used by Pellow et al.. For P2H we use their estimate for large- 
608 All data used in this analysis were based on published studies that are duly referenced in the text and the related tables. 609 Any assumptions, adjustments and normalizations are described in the captions or the text. The annotated code used to 610 run the analysis and develop the figures can be openly accessed on Github

\section{1 (http://nbviewer.jupyter.org/github/csaladenes/sustainable-energy-transitions/blob/master/ccs/eroei-ccs-}

612 workbook.ipynb ). The corresponding author will make available any additional information upon reasonable request.

\section{3}

\section{Competing interests}

- The authors declare no financial and non-financial competing interests.

616

617

618

619

620

621

622

623

624

625

626

627

628

629

630

631

\section{Author contributions}

- SS conceived of the research idea, conducted the initial analysis, collected data and authored the majority of the text. MD authored parts of the text, reviewed the analysis, proposed changes, contributed to data collection. DC developed the sensitivity analysis models, the code for the figures, checked and contributed to the analysis. UB reviewed and edited the manuscript and contributed parts of the text. MC reviewed and edited the manuscripte and proposed changes for its organization and structure.

- The corresponding author for any questions, comments and request for materials is Sgouris Sgouridis (Sgouris.sgouridis@ku.ac.ae, sgouris@alum.mit.edu ).

\section{Acknowledgments}

We would like to thank the organizers and participants of the ECI CO2 Summit for their comments and discussion and especially Dr. Jennifer Wilcox, and Dr. Niall McDowell for their feedback on the original idea. We would also like to thank Masdar Institute for supporting our participation. 